\title{
Comparison of the Effect of Two Doses of Vitamin D (Vit D-Ca and Vit D-Ca+Vit D) from the 16th Week on Preterm Labor in Pregnant Women
}

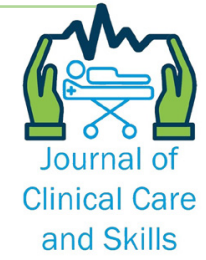

\section{ART ICLE INFO}

\section{Article Type}

Original Research

\section{Authors}

Mosallanejad N.S. ${ }^{1} P h D$,

Taghavi A.V. ${ }^{1} P h D$

Saadat M. ${ }^{1} P h D$,

RaJaii M. ${ }^{1} P h D$,

Bazarganipour F.*PhD

\section{A B S T RAC T}

Aims Preterm labor (delivery earlier than 37 weeks) is one of the most common problems with midwifery. Recently, vitamin D deficiencies have been reported with adverse maternal outcomes such as pregnancy toxicity, intrauterine growth limitation, and preterm labor. The aim of this study was to compare the effect of 2 doses of vitamin D (Vit D-Ca and Vit D-Ca+Vit D) from the 16th week on preterm labor in pregnant women.

Materials \& Methods The present single-blind randomized clinical trial was conducted on 202 pregnant women referred to 5 obstetric and gynecological clinics in Bandar Abbas, Hormozgan province, Iran during January 2016 to March 2017. The subjects were selected by randomization sampling method and were randomly assigned into group $A(n=150)$ and group B ( $\mathrm{n}=152)$. Group A received Vit D-Ca supplements, containing $400 \mathrm{IU} /$ day, and group B received Vit D-Ca supplement plus Vit D (with D3 brand), containing 1000 IU/day from the 16th week of pregnancy until delivery. The subjects were examined from the 16 th week of pregnancy until delivery. The data were analyzed by SPSS 21 software, using independent t-test, Mann-Whitney U test and Chi-square test.

Findings The incidence of preterm labor in the group receiving Vit D-Ca+Vit D (group B) was $24(16.0 \%)$ and in the group receiving Vit D-Ca alone was $25(16.7 \%)$. There was a significant difference between the two groups in terms of preterm labor $(p=0.01)$.

Conclusion Vit D-Ca plus Vit D intake reduces preterm labor in pregnant women more than Vit D-Ca alone intake.

Keywords Vitamin D; Preterm Labor; Pregnancy
*Social Determinants of Health Research Center, Yasuj University of Medical Sciences, Yasuj, Iran ${ }^{1}$ Gynecology \& Obstetrics Department, Hormozgan University of Medical Sciences, Hormozgan, Iran

\section{Correspondence}

Address: Floor 3, Gynecology \& Obstetrics Department, Medicine Faculty, Campus of Yasuj University of Medical Sciences, Yasuj, Iran

Phone: +98 (74) 33235041

Fax: +98 (74) 33235041

f.bazarganipour@gmail.com

\section{Article History}

Received: November 15, 2017

Accepted: January 25, 2018

ePublished: March 10, 2020

\section{CIT A T I ON LINKS}

[1] Born too soon: The global action report ... [2] Preterm birth: Causes, consequences ... [3] Association between maternal serum 25-hydroxyvitamin D level ... [4] Post-hoc comparison of vitamin D status at three timepoints ... [5] Early-pregnancy vitamin D deficiency and risk of preterm ... [6] Associations between 25-hydroxyvitamin D levels ... [7] Vitamin D deficiency in early ... [8] Associations of maternal circulating 25-hydroxyvitamin D3 ... [9] The vitamin D deficiency pandemic: A forgotten hormone ... [10] Vitamin D and Pregnancy ... [11] Vitamins for chronic disease prevention ... [12] Evaluation, treatment, and prevention of vitamin D ... [13] Vitamin D deficiency and insufficiency in ... [14] Vitamin D deficiency in pregnant New Zealand ... [15] Vitamin D status of mothers and their ... [16] High prevalence of vitamin D deficiency in pregnant ... [17] Vitamin D deficiency in Iranian mothers ... [18] Does vitamin D during pregnancy impact ... [19] Vitamin D supplementation in ... [20] Committee Opinion No. 495: Vitamin D: Screening ... [21] The national monitoring system for food and nutrition ... [22] Maternal 25-hydroxyvitamin d and preterm ... [23] Maternal 25-hydroxyvitamin D and parathyroid ... [24] Vitamin D status and recurrent preterm ... [25] Maternal vitamin D status in pregnancy and ... [26] A nested case-control study of first-trimester maternal vitamin ... [27] Vitamin D and pregnancy: Skeletal effects, nonskeletal ... [28] Vitamin D induces innate antibacterial responses ... [29] Effects of 25-hydroxyvitamin D3 and 1,25 ... [30] Vitamin D and the regulation of placental ... [31] Dietary reference intakes for calcium ... [32] Evidence for alteration of the vitamin D ... 


\section{Introduction}

Preterm labor (delivery earlier than 37 weeks) is one of the most common problems with midwifery, resulting in death of over 1 million newborns worldwide, and it is the second leading cause of death in children younger than 5 years [1]. The detection of high-risk individuals to prevent preterm labor is considered a health priority [1-3]. Recently, vitamin D deficiencies have been reported with adverse maternal outcomes such as pregnancy toxicity, intrauterine growth limitation, and preterm labor; however, their results are contradictory. Based on some studies, vitamin D deficiency during pregnancy is associated with an increased risk of preterm labor. Wagner et al. have reported that vitamin D serum levels lower than $20 \mathrm{ng} / \mathrm{ml}$ increase the risk of preterm labor 3.81 times more than vitamin D serum levels more than $40 \mathrm{ng} / \mathrm{ml}{ }^{[4]}$. Bodnar et al. reported that the risk of preterm labor with vitamin D serum level of $36 \mathrm{ng} / \mathrm{ml}$ is reduced and, then, reaches to a constant level [5]. Zhou et al. reported that vitamin $D$ deficiency is associated with lower risk of preterm labor. They found that the prevalence of preterm labor was higher in 25(OH)D (25-hydroxy vitamin D) $\geq 30 \mathrm{ng} / \mathrm{ml}$ than the low level ( $\leq 20 \mathrm{ng} / \mathrm{ml}$ ) and medium level $(20-30 \mathrm{ng} / \mathrm{ml})$ in southern China [6]. However, Flood et al. and Rodriguez et al. reported that vitamin D deficiency during pregnancy is not associated with preterm labor $[7,8]$.

Vitamin D is a unique and essential micronutrient, whose main and important function is maintaining calcium homeostasis and skeletal well-being. With the deficiency of this vitamin, only $10 \%$ to $15 \%$ of calcium and $60 \%$ of phosphorus can be absorbed [9]. Low levels of vitamin D (lower than normal) are one of the problems of the community in the 21st century [10,11]. Serum levels of 25(OH)D more than $30 \mathrm{ng} / \mathrm{ml}$ and less than $20 \mathrm{ng} / \mathrm{ml}$ were considered ideal and deficient statuses, respectively [12]. Levels of $25(\mathrm{OH}) \mathrm{D}$ less than $25 \mathrm{ng} / \mathrm{ml}$ during pregnancy in pregnant women were $17 \%$ to $18 \%$ in Caucasus, $61 \%$ in New Zealand, $32 \%$ to $42 \%$ in India, $59 \%$ to $84 \%$ in Kuwait, $84 \%$ in Iran, and 75\% in UAE [13-17]. Low levels of vitamin D during pregnancy have been effective on maternal and fetal calcium homeostasis and are expected to affect bone development [18].

Currently, the recommendations for daily intake of vitamin D vary from 400 to 600 IU (Medical Association), 1500 to 2000 IU (Endocrinology Association), and 2000 IU (Canadian Association) [19]. According to the Royal College of Obstetricians and Gynecologists, in terms of vitamin D supplementation intake, people are divided into 3 groups: Normal people, 400 IU should be available to all pregnant women, high-risk people, $1000 \mathrm{IU}$ such as obese or dark-skinned women, and 2000 IU involved with the Cholecalciferol treatment at least taking 4 to 6 weeks for those who have deficiency. Many specialists agree to 1000 to $2000 \mathrm{IU} /$ day, and Journal of Clinical Care and Skills it is suggested that even up to a dose of $4000 \mathrm{IU} /$ day is safe in pregnancy and lactation [20].

The prevalence of vitamin D deficiency in the Middle East is much higher than in the United States and Europe; it seems that how to wear is a significant factor in the incidence of vitamin D deficiency in the Muslim and Middle Eastern countries [12]. Hormozgan province is one of the deprived southern provinces of Iran that, based on the Ministry of Health, is in an unfavorable situation in terms of malnutrition and food insecurity [21]. The shortage of micronutrients and all types of vitamins in high-risk groups, including pregnant women, is on the rise. Regarding the mentioned issues and lack of research on the relationship between vitamin $\mathrm{D}$ and preterm labor in Iran, the aim of this study was to compare the effect of 2 doses of vitamin D (Vit D-Ca and Vit D$\mathrm{Ca}+$ Vit D) from the 16 th week on preterm labor in pregnant women.

\section{Materials and Methods}

The present single-blind randomized clinical trial was conducted on pregnant women referred to 5 obstetric and gynecological clinics in Bandar Abbas, Hormozgan province, Iran during January 2016 to March 2017. After approving the research at the Ethics Committee of Hormozgan University of Medical Sciences, the subjects were selected by randomization sampling method by computer generation.

At first, 420 people were evaluated, of whom 10 were not eligible. Therefore, 410 subjects entered the study by presenting written consent. They were randomly assigned into group A and group B (205 people in each group), using homogeneous and similar envelopes. Of group A, 45 subjects and of group B, 41 subjects left the study for personal reasons. In the next step, 10 subjects in group A and 12 subjects in group B were excluded due to fear of side effects and Ca-D intolerance. Finally, 150 subjects in group A and 152 subjects in group B remained. Considering $50 \%$ loss, the sample size was estimated at least 150 people per group [4].

Inclusion criteria consisted of gestational age less than 10 weeks, no history of diabetes and blood pressure, Iranian nationality, no history of polycystic ovaries, no history of diabetes and blood pressure in first-degree relatives, willingness to participate in the study, body mass index (BMI) between 19 to $26 \mathrm{Kg} / \mathrm{m}^{2}$, no intake of vitamin $\mathrm{D}$ in the last 6 months, single pregnancy, and vitamin D levels ranged between $30-70 \mathrm{ng} / \mathrm{ml}$. Exclusion criteria consisted of embryos with anomalies, reluctance to participate in the study, thyroid and parathyroid diseases, kidney disease (Creatinine $>2$ ), known liver disease, sarcoidosis, tuberculosis, consumption of anticonvulsant medications or drugs such as corticosteroids that affect metabolism of vitamin D and calcium.

The researcher did not know about the allocation of 
subjects to the studied groups. Group A received Vit D-Ca supplements, containing $400 \mathrm{IU} /$ day from the 16th week of pregnancy until delivery, and group B received Vit D-Ca supplement plus Vit D (with D3 brand), containing 1000 IU/day (Zahravi; Tabriz, Iran) from the 16th week of pregnancy until delivery. The subjects were examined from the 16th week of pregnancy until delivery. The care intervals were based on the guideline of Ministry of Health and the measures taken were listed (Table 1).

The data were analyzed by SPSS 21 software, using Kolmogorov-Smirnov test to examine the normal distribution of data, independent t-test for quantitative variables (age, educational level of the pregnant women and husbands), and Mann-Whitney $\mathrm{U}$ test and Chi-square test for qualitative and ranking variables (gravid, parity, number of children, abortion, and stillborn).

Table 1) Measures taken at each visit of pregnant women in group A $(n=150)$ and group B $(n=152)$

Weeks 10-15
- Mother information: age, Body Mass Index, educational level and
occupation
- Weight and blood pressure measurement
- Common tests include FBS, CBC/Diff, BUN/Cr, and UA/UC
-PUQE index for evaluating nausea and vomiting
Weeks 16-20
- Weight and blood pressure measurement
- PUQE index for evaluating nausea and vomiting
- Cervical incompetence measurement
- Request preterm delivery ultrasonography at weeks 16-18
-(Formulation, evaluation of amniotic fluid volume)
Weeks 26-30
- Weight and blood pressure measurement
- Common tests include FBS, CBC/Diff, BUN/Cr, and UA/UC
Weeks 31-34
- Weight and blood pressure measurement
Request preterm delivery ultrasonography at weeks 31-34
(evaluation of amniotic fluid volume, fetal growth and placenta
evaluation)
Weeks 35-37
- Weight and blood pressure measurement

\section{Findings}

The two groups (A and B) did not significantly differ in terms of age, educational years of women and their husbands, gravid, parity, abortion, number of children, stillborn, and first-trimester visit (Tables 2, 3 , and 4).

The incidence of preterm labor in the group receiving Vit D-Ca+Vit D (group B) was 24 (16.0\%) and in the group receiving Vit D-Ca alone was 25 (16.7\%). There was a significant difference between the two groups in terms of preterm labor $(p=0.01)$.

Table 2) Comparison of the mean age and educational level of pregnant women and their husbands in group $A(n=150)$ and $B$

\begin{tabular}{|c|c|c|c|}
\hline Group A & Group B & $\mathbf{t}$ & P.value \\
\hline \multicolumn{4}{|l|}{ Age (years) } \\
\hline $26.84 \pm 4.71$ & $26.14 \pm 4.72$ & 1.48 & 0.13 \\
\hline \multicolumn{4}{|c|}{ Educational level (years) } \\
\hline $12.50 \pm 2.97$ & $12.45 \pm 3.17$ & 0.18 & 0.85 \\
\hline \multicolumn{4}{|c|}{ Educational level of husband (years) } \\
\hline $14.33 \pm 2.42$ & $14.44 \pm 2.51$ & 0.43 & 0.66 \\
\hline
\end{tabular}

Table 3) Comparison of the absolute and relative frequency of (numbers in parentheses are percentages) variables related to pregnancy in group A $(n=150)$ and group B $(n=152)$

\begin{tabular}{|c|c|c|c|}
\hline Variables & Group A & Group B & P.value \\
\hline \multicolumn{4}{|c|}{ Gravid (pregnancy) } \\
\hline First & $84(56.0)$ & $82(53.9)$ & \multirow{3}{*}{0.99} \\
\hline Second & $36(24.0)$ & $50(32.9)$ & \\
\hline Third & $30(20.0)$ & $20(13.2)$ & \\
\hline \multicolumn{4}{|c|}{ Parity (pregnancy date to week 20) } \\
\hline Zero & $76(50.7)$ & $103(67.8)$ & \multirow{3}{*}{0.79} \\
\hline One & $27(18.0)$ & $40(26.3)$ & \\
\hline Two & $47(31.3)$ & $9(5.9)$ & \\
\hline \multicolumn{4}{|l|}{ Abortion } \\
\hline Zero & $117(78.0)$ & 120 (78.9) & \multirow{2}{*}{0.92} \\
\hline One & $33(22.0)$ & $32(21.1)$ & \\
\hline \multicolumn{4}{|c|}{ Number of children } \\
\hline Zero & $114(76.0)$ & $119(78.3)$ & \multirow{3}{*}{0.43} \\
\hline One & $30(20.0)$ & $24(15.8)$ & \\
\hline Two & $6(40)$ & $9(5.9)$ & \\
\hline \multicolumn{4}{|c|}{ Number of stillborn } \\
\hline Zero & $141(94.0)$ & $136(89.5)$ & \multirow{2}{*}{0.6} \\
\hline One & $9(6.0)$ & $16(10.5)$ & \\
\hline
\end{tabular}

Table 4) Comparison of the levels of biochemical variables in the first visit (first trimester) between groups $A(n=150)$ and $B$

\begin{tabular}{lcccc}
\multicolumn{1}{c}{ Variables } & Group A & Group B & t & P.value \\
\hline Hb $(\mathrm{g} / \mathrm{dL})$ & $11.07 \pm 1.43$ & $11.35 \pm 1.42$ & 1.98 & 0.7 \\
$\begin{array}{l}\text { Platelet } \\
\left(\times 10^{9} / \mathrm{L}\right)\end{array}$ & $277.37 \pm 48.35$ & $279.17 \pm 50.02$ & 0.37 & 0.71 \\
MCV & & & & \\
(femtoliter) & $80.77 \pm 4.76$ & $81.81 \pm 4.43$ & 2.25 & 0.6 \\
FBS $(\mathrm{mg} / \mathrm{dl})$ & $79.11 \pm 6.54$ & $79.40 \pm 6.25$ & 0.46 & 0.64 \\
BUN $(\mathrm{mg} / \mathrm{dl})$ & $14.24 \pm 2.59$ & $14.15 \pm 2.67$ & 0.32 & 0.74 \\
Cr $(\mathrm{mg} / \mathrm{dl})$ & $0.68 \pm 0.60$ & $0.63 \pm 0.13$ & 1.04 & 0.290 \\
\hline
\end{tabular}

\section{Discussion}

The aim of this study was to compare the effect of 2 vitamin D doses (Vit D-Ca and Vit D-Ca+Vit D) on preterm labor in pregnant women in Hormozgan province, Iran. The effect of the deficiency and inadequate level of vitamin $\mathrm{D}-\mathrm{Ca}$ on the consequences of pregnancy has been controversial; although observational research studies have reported limited results, there are currently few guidelines on the management of vitamin $D$ in pregnancy. The present study showed that the prevalence of preterm labor in the Vit D-Ca plus Vit D was significantly lower than Vit D-Ca alone.

Due to the well-known association of vitamin D deficiency and inflammatory symptoms, some studies have suggested vitamin D in preventing preterm labor. Some studies have shown that the level of 25(OH)D in pregnancy has a negative correlation with the risk of preterm labor or reduces the gestational age [22, 23]. However, some studies have not shown such an association [24, 25]. Previous studies were conducted in twin pregnancy on American Pregnant women [22] and Tanzanian mothers infected with the HIV virus [19]. In a study in North Carolina, in women with preterm labor and lack of chorioamnionitis, there was no association between the first-trimester vitamin $D$ level and per se preterm labor [26].

There are also few research studies on the effects of vitamin $\mathrm{D}$ and preterm labor. Only one study has 
Comparison of the Effect of Two Doses of Vitamin D (Vit D-Ca and ... shown that vitamin D did not affect preterm labor before 37 weeks in doses of 2000-4000 IU from 12th to 16 th weeks of pregnancy until delivery. However, this study was designed to assess safety and lacked sufficient statistical power to evaluate the effect of Vit D supplement on adverse pregnancy outcomes [27].

To date, the pathophysiological mechanisms involved in preterm labor have been important. In fact, preterm labor is a syndrome, but there is strong evidence showing that intrauterine infection is a common mechanism for this type of labor. It has been suggested that vitamin D affects the physiological pathways involved in the preterm labor pathogenesis, such as inflammation, immunomodulation, and the translation of the genes involved in the pair function [28-30]. The differences in the current research and earlier studies may be due to racial differences affecting the vitamin D function that has already been proven [31] and includes heterozygosity in parathyroid function, expression of vitamin D receptor, protein bounded to vitamin D, or enzymes involved in the metabolism of vitamin D [32].

One of the limitations of the present study is not measuring other symptoms involved in the metabolism of vitamin $D$. The concentration of protein bounded to vitamin D affects bioavailability of $25(\mathrm{OH}) \mathrm{D}$. Because $25(\mathrm{OH}) \mathrm{D}$ is bounded to the vitamin $\mathrm{D}$ binding protein and the serum level of $25(\mathrm{OH}) \mathrm{D}$ alone is an inadequate indicator of vitamin D function [27]. The 2000 IU/day dose was not available in Iran and $1000 \mathrm{IU} /$ day pill was selected due to poor compliance and poor financial condition of pregnant women in Hormozgan province. Also, the random selection of the present research population may not be true for the whole Hormozgan province and limit the generalizability of the findings. It is suggested to conduct clinical trials with larger sample sizes.

\section{Conclusion}

Vit D-Ca plus Vit D intake reduces preterm labor in pregnant women more than Vit D-Ca alone intake.

Acknowledgments: The authors appreciate the research deputy of Hormozgan University of Medical Sciences because of their support and also thank the participants who sincerely cooperated in this study.

Ethical Permissions: The Ethics Committee of Hormozgan University of Medical Sciences approved this study. Informed consent was obtained from all subjects. According to the ACOG guidelines, receiving $4000 \mathrm{IU} /$ day vitamin $\mathrm{D}$ during pregnancy is safe. The registration code on the international clinical trial site is RCT2016121430612N2.

Conflict of Interests: The authors declare that there is no conflict of interests.

Authors' Contribution: Mosallanejad N.S. (First author), Introduction author/ Methodologist/
Original researcher/ Discussion author (20\%); Taghavi A.V. (Second author), Methodologist/ Assistant (20\%); Saadat M. (Third author), Methodologist/ Assistant (20\%); RaJaii M. (Fourth author), Introduction author/ Methodologist/ Discussion author (20\%); Bazarganipour F. (fifth author), Introduction author/ Methodologist / Statistical analyst/ Discussion author (20\%)

Funding: The present research was funded by Hormozgan University of Medical Sciences, Iran.

\section{References}

1- March of Dimes. Born too soon: The global action report on preterm birth. Switzerland: World Health Organization; 2012.

2- Institute of Medicine. Preterm birth: Causes, consequences, and prevention. Washington, DC: National Academy of Sciences; 2006.

3- Aghajafari F, Nagulesapillai T, Ronksley PE, Tough SC, O'Beirne M, Rabi DM. Association between maternal serum 25-hydroxyvitamin D level and pregnancy and neonatal outcomes: Systematic review and meta-analysis of observational studies. Br Med J. 2013;346:f1169.

4- Wagner CL, Baggerly C, McDonnell SL, Baggerly L, Hamilton SA, Winkler J, et al. Post-hoc comparison of vitamin $D$ status at three timepoints during pregnancy demonstrates lower risk of preterm birth with higher vitamin D closer to delivery. J Steroid Biochem Mol Biol. 2015;148:256-60.

5- Bodnar LM, Platt RW, Simhan HN. Early-pregnancy vitamin D deficiency and risk of preterm birth subtypes. Obstet Gynecol. 2015;125(2):439-47.

6- Zhou J, Su L, Liu M, Liu Y, Cao X, Wang Z, et al. Associations between 25-hydroxyvitamin D levels and pregnancy outcomes: A prospective observational study in southern China. Eur J Clin Nutr. 2014;68(8):925-30.

7- Flood-Nichols SK, Tinnemore D, Huang RR, Napolitano PG, Ippolito DL. Vitamin D deficiency in early pregnancy. PLoS One. 2015;10(4):e123763.

8- Rodriguez A, Garcia-Esteban R, Basterretxea M, Lertxundi A, Rodriguez-Bernal C, Iniguez C, et al. Associations of maternal circulating 25-hydroxyvitamin D3 concentration with pregnancy and birth outcomes. Bjog. 2015;122(12):1695-704.

9- Holick MF. The vitamin D deficiency pandemic: A forgotten hormone important for health. Pub Health Rev. 2010;32(1):267-83.

10- - Zarean E, Jamal AS. Vitamin D and Pregnancy. Iran J Obstet Gynecol Infertil. 2011;6(3):13-20. [Persian]

11- Fairfield KM, Fletcher RH. Vitamins for chronic disease prevention in adults: Scientific review. Jama. 2002;287(23):3116-26.

12- Holick MF, Binkley NC, Bischoff-Ferrari HA, Gordon CM, Hanley DA, Heaney RP, et al. Evaluation, treatment, and prevention of vitamin D deficiency: An Endocrine Society clinical practice guideline. J Clin Endocrinol Metab. 2011;96(7):1911-30.

13- Holmes VA, Barnes MS, Alexander HD, McFaul P, Wallace JM. Vitamin D deficiency and insufficiency in pregnant women: A longitudinal study. $\mathrm{Br} \mathrm{J}$ Nutr. 2009;102(6):876-81.

14- Judkins A, Eagleton C. Vitamin D deficiency in pregnant New Zealand women. $\mathrm{N} Z$ Med J. 2006;119(1241):U2144.

15- Molla AM, Al Badawi M, Hammoud MS, Shukkur M, 
47

Thalib L, Eliwa MS. Vitamin D status of mothers and their neonates in Kuwait. Pediatr Int. 2005;47(6):649-52.

16- van der Meer IM, Karamali NS, Boeke AJ, Lips P, Middelkoop BJ, Verhoeven I, et al. High prevalence of vitamin D deficiency in pregnant non-western women in the hague, Netherlands. Am J Clin Nutr. 2006;84(2):350-3.

17- Bassir M, Laborie S, Lapillonne A, Claris 0, Chappuis MC, Salle BL. Vitamin D deficiency in Iranian mothers and their neonates: A pilot study. Acta Paediatr. 2001;90(5):577-9.

18- Specker BL. Does vitamin D during pregnancy impact offspring growth and bone?. Proc Nutr Soc. 2012;71(1):38-45.

19- Mithal A, Kalra S. Vitamin D supplementation in pregnancy. Indian J Endocrinol Metab. 2014;18(5):593-6.

20- The American College of Obstetricians and Gyneocologists. Committee Opinion No. 495: Vitamin D: Screening and supplementation during pregnancy. Obstet Gynecol. 2011;118(1):197-8.

21- Kolahdooz F, Najafi F. The national monitoring system for food and nutrition in iran and the first map of the state of food security in Iran. Tehran: Ministry of Health and Medical Education; 2012. [Persian]

22- Bodnar LM, Rouse DJ, Momirova V, Peaceman AM, Sciscione A, Spong CY, et al. Maternal 25-hydroxyvitamin d and preterm birth in twin gestations. Obstet Gynecol. 2013;122(1):91-8.

23- Morley R, Carlin JB, Pasco JA, Wark JD. Maternal 25hydroxyvitamin $\mathrm{D}$ and parathyroid hormone concentrations and offspring birth size. J Clin Endocrinol Metab. 2006;91(3):906-12.

24- Thorp JM, Camargo CA, McGee PL, Harper M, Klebanoff
Mosallanejad N.S. et al.

MA, Sorokin Y, et al. Vitamin D status and recurrent preterm birth: A nested case-control study in high-risk women. Bjog. 2012;119(13):1617-23.

25- Shand AW, Nassar N, Von Dadelszen P, Innis SM, Green TJ. Maternal vitamin D status in pregnancy and adverse pregnancy outcomes in a group at high risk for preeclampsia. Bjog. 2010;117(13):1593-8.

26- Baker AM, Haeri S, Camargo CA Jr, Stuebe AM, Boggess KA. A nested case-control study of first-trimester maternal vitamin D status and risk for spontaneous preterm birth. Am J Perinatol. 2011;28(9):667-72.

27- Hollis BW, Wagner CL. Vitamin D and pregnancy: Skeletal effects, nonskeletal effects, and birth outcomes. Calcif Tissue Int. 2013;92(2):128-39.

28- Liu N, Kaplan AT, Low J, Nguyen L, Liu GY, Equils O, et al. Vitamin D induces innate antibacterial responses in human trophoblasts via an intracrine pathway. Biol Reprod. 2009;80(3):398-406.

29- Evans KN, Nguyen L, Chan J, Innes BA, Bulmer JN, Kilby MD, et al. Effects of 25-hydroxyvitamin D3 and 1,25dihydroxyvitamin D3 on cytokine production by human decidual cells. Biol Reprod. 2006;75(6):816-22.

30- Liu NQ, Kaplan AT, Lagishetty V, Ouyang YB, Ouyang Y, Simmons CF, et al. Vitamin D and the regulation of placental inflammation. J Immunol. 2011;186(10):596874.

31- Del Valle HB, Yaktine AL, Taylor CL, Ross AC. Dietary reference intakes for calcium and vitamin D. Washington DC: National Academies Press; 2011.

32- Bell NH, Greene A, Epstein S, Oexmann MJ, Shaw S, Shary J. Evidence for alteration of the vitamin D-endocrine system in blacks. J Clin Invest. 1985;76(2):470-3. 